\title{
Influência da Cola Bioglue® na Deiscência de Anastomose Colônica. Estudo Experimental
}

\author{
Influence of Bioglue® Surgical Adhesive on colonic anastomosis dehiscence. \\ Experimental study
}

\author{
MAURILIO TOSCANO DE LUCENA ${ }^{1}$-ASBCP; CARLOS AUGUSTO MATHIAS ${ }^{2}$; NICODEMOS TELES DE PONTES \\ FILHO ${ }^{3}$; ANACLÁUDIALUNACÂNDIDO ${ }^{4} ;$ EMILIANA VASCONCELOS $^{5}$
}

\begin{abstract}
${ }^{1}$ Médico Coloproctologista do Hospital Barão de Lucena, Recife-PE; ${ }^{2}$ Prof ${ }^{o}$ do Departamento de Cirurgia - Centro de Ciências da Saúde, Universidade Federal de Pernambuco; ${ }^{3}$ Prof ${ }^{o}$ do Departamento de Patologia - Centro de Ciências da Saúde, Universidade Federal de Pernambuco; ${ }^{4}$ Médica Residente do Serviço de Coloproctologia do Hospital Barão de Lucena, Recife-PE; ${ }^{5}$ Acadêmica de Medicina da Universidade Federal de Pernambuco.
\end{abstract}

LUCENA MT; MATHIAS CA; PONTES FILHO NT; CÂNDIDO ACL; VASCONCELOS E. Influência da Cola Bioglue® na Deiscência de Anastomose Colônica. Estudo Experimental. Rev bras Coloproct, 2007;27(2): 158-166.

RESUMO: A grande parte da morbimortalidade associada com a cirurgia colorretal, é associada com a deiscência anastomótica. Trabalhos experimentais sobre a utilidade de adesivos tissulares nas anastomoses colônicas são controversos, assim como estudos clínicos prospectivos randomizados são ausentes. $O$ adesivo cirúrgico BioGlue®, formado por dois componentes - albumina sérica bovina purificada e glutaraldeído, forma uma ligação co-valente entre esses dois componentes e as proteínas teciduais no local de aplicação. $O$ objetivo do estudo é avaliar a eficácia da BioGlue ${ }^{\circledR}$ na prevenção da deiscência anastomótica colônica em ratos. Foram utilizados 30 ratos machos da raça Wistar albino. A anastomose colocolônica foi confeccionada com sutura em pontos separados com polipropileno 5-0 (grupo 1) e aplicação da cola BioGlueß envolvendo a anastomose (grupo 2). Avaliaram-se a formação e extensão das aderências, a pressão de ruptura nas anastomoses e as alterações histológicas. Apenas um animal do grupo 1 (7\%) faleceu, sendo constatada na necropsia, obstrução intestinal com grande distensão de alças. A mortalidade no grupo 2, por outro lado, foi de 10 animais (67\%), sendo observado: distensão de alças intestinais, vazamento anastomótico e, em algumas situações, franca peritonite fecal por deiscência quase que total da anastomose. $O$ presente trabalho nos permitiu concluir que, o uso da Bioglue ${ }^{\circledR}$ nas anastomoses colônicas realizadas em ratos, promoveu um aumento na morbimortalidade que foi estatisticamente significante comparado à sutura convencional.

Descritores: Bioglue $® ;$ deiscência; anastomose colônica.

\section{INTRODUÇÃO}

Uma grande parte da morbimortalidade associada com a cirurgia colorretal, é conseqüência da deiscência anastomótica ${ }^{1-5}$, que pode ser decorrente de uma série de fatores: fornecimento inadequado de oxigênio, tensão mecânica elevada, grande contaminação bacteriana e problemas técnicos (tipo de sutura utilizada etc. $)^{6-8}$.
Os cirurgiões estão constantemente em busca do aperfeiçoamento nas técnicas de confecção das anastomoses, utilizando, por exemplo, materiais de sutura que provocam menos reações, dispositivos mecânicos tais como os grampeadores, anéis biofragmentáveis e colas adesivas ${ }^{9-12}$. Embora algumas dessas inovações técnicas tenham reduzido drasticamente as taxas de deiscência anastomótica, este ainda é um importante problema nos procedimentos cirúrgi-

Trabalho realizado no Biotério e no Setor de Patologia do Laboratório de Imunopatologia Keizo Asami (LIKA-UFPE).

Recebido em 24/04/2007

Aceito para publicação em 30/05/2007 
cos sobre o cólon, atingindo cifras de até $5 \%$ em cirurgias eletivas e 10-15\% em cirurgias de emergência ${ }^{13,14}$. Trabalhos experimentais sobre a utilidade de adesivos tissulares nas anastomoses colônicas são controversos, assim como estudos clínicos prospectivos randomizados são ausentes ${ }^{12,15-20}$.

O adesivo cirúrgico BioGlue ${ }^{\circledR}$, formado por dois componentes - albumina sérica bovina purificada e glutaraldeído, forma uma ligação co-valente entre esses dois componentes e as proteínas teciduais no local de aplicação. Desta maneira, é formado um revestimento mecânico flexível, independentemente dos mecanismos de coagulação do organismo. $\mathrm{O}$ adesivo cirúrgico BioGlue ${ }^{\circledR}$ poderia ser útil nas anastomoses digestivas, promovendo uma barreira física em torno das mesmas, diminuindo as taxas de deiscência no período pós-operatório, aumentando a resistência mecânica e a pressão de ruptura ${ }^{21}$

A principal indicação do adesivo cirúrgico BioGlueÒ tem sido na hemostasia adjuvante aos métodos padrões (tais como suturas, grampeadores), nas cirurgias abertas de reparo de grandes vasos (tais como aorta, femoral e carótida) em pacientes adultos ${ }^{21}$.

Não identificamos na literatura pesquisada, estudos avaliando os efeitos dos adesivos teciduais à base de albumina-glutaraldeido nas anastomoses colônicas.

Os objetivos do presente trabalho foram avaliar clinicamente os efeitos da BioGlue ${ }^{\circledR}$ sobre as anastomoses colônicas - integridade, existência de abscesso perianastomótico, presença de peritonite, formação de aderências e pressão de ruptura anastomótica - assim como proceder à avaliação histológica infiltrado celular inflamatório, atividade fibroblástica, neoangiogênese e deposição de colágeno.

\section{MATERIAIS E MÉTODOS}

O protocolo experimental desenvolvido no presente trabalho foi submetido à aprovação pela comissão de ética em experimentação animal do Centro de Ciências Biológicas da Universidade Federal de Pernambuco (CCB-UFPE).

\section{Animais}

Foram utilizados 30 ratos machos da raça Wistar albino, pesando entre 280-410g, com idades variando entre 90 e 120 dias. Os animais foram mantidos em gaiolas individuais em ciclos de 12 horas alter- nando-se claro/escuro e temperatura ambiente entre 20 e $25^{\circ} \mathrm{C}$, com dieta comercial Labina ${ }^{\circledR}$ contendo $23 \%$ de proteínas e oferecido alimento e água " $a d$ libitum".

Após uma noite de jejum, os animais foram operados e distribuídos em dois grupos:

Grupo 1 - Ratos submetidos à anastomose colocolônica convencional utilizando-se fios de sutura;

Grupo 2 - Ratos submetidos à anastomose colocolônica convencional utilizando-se fios de sutura e cola BioGlue ${ }^{\circledR}$.

Imediatamente após o sacrifício, realizado 10 dias após a $1^{\text {a }}$ cirurgia, os animais foram acondicionados em recipientes adequados, congelados e coletados pelo Serviço Municipal de Lixo de Biotério.

\section{Procedimentos Cirúrgicos}

Todos os procedimentos cirúrgicos fora realizados pelo mesmo cirurgião.

Os animais receberam anestesia por via intramuscular, utilizando-se cloridrato de cetamina $(50 \mathrm{mg} / \mathrm{kg})$ e cloridrato de xilazina $(50 \mathrm{mg} / \mathrm{kg})$. Realizou-se a contenção em bandeja própria e procedeu-se a tricotomia da região abdominal.

Após a antissepsia com solução polivinilpirrolidona iodo, o abdome foi incisado na linha média e realizada transecção do cólon aproximadamente $3 \mathrm{~cm}$ acima da reflexão peritoneal. A anastomose colocolônica foi confeccionada com sutura em pontos separados extramucosos término-terminais com polipropileno 5-0 (grupo 1). Os animais do grupo 2, foram submetidos à anastomose colocolônica com sutura em pontos separados extramucosos término-terminais com polipropileno 5-0 e aplicação de $0,5 \mathrm{ml}$ da cola BioGlue ${ }^{\circledR}$ cobrindo a anastomose, e tomando-se o cuidado para evitar a dispersão da cola na cavidade peritoneal (figura 1). A parede abdominal foi fechada em dois planos com sutura contínua utilizando-se polipropileno 4-0 interessando a aponeurose e a pele.

Dez dias após a cirurgia, os animais foram sacrificados com uma "overdose" de anestésicos e secção da veia cava e aorta para induzir hipovolemia. A parede abdominal foi novamente aberta através da incisão longitudinal mediana prévia.

\section{Avaliação Macroscópica e Pressão de Ruptura da Anastomose}

A extensão das aderências foi descrita de acordo com a classificação de Mazuji 22 e a área da 
anastomose examinada quanto à presença de vazamento, estenose, peritonite além de infecção da ferida cirúrgica (figura 2). A pressão de ruptura foi determinada através da ressecção de um segmento de $\pm 5 \mathrm{~cm}$ do cólon englobando a área da anastomose, ligando-se a extremidade proximal com fio de seda 3-0 e passandose um cateter conectado a um esfingomanômetro na extremidade distal fixado com ligadura. Por meio deste cateter, era injetado ar numa das aberturas da "torneirinha de tri-way" e, ao evidenciar-se o surgimento das primeiras bolhas na água em que o segmento do cólon encontrava-se submerso, considerou-

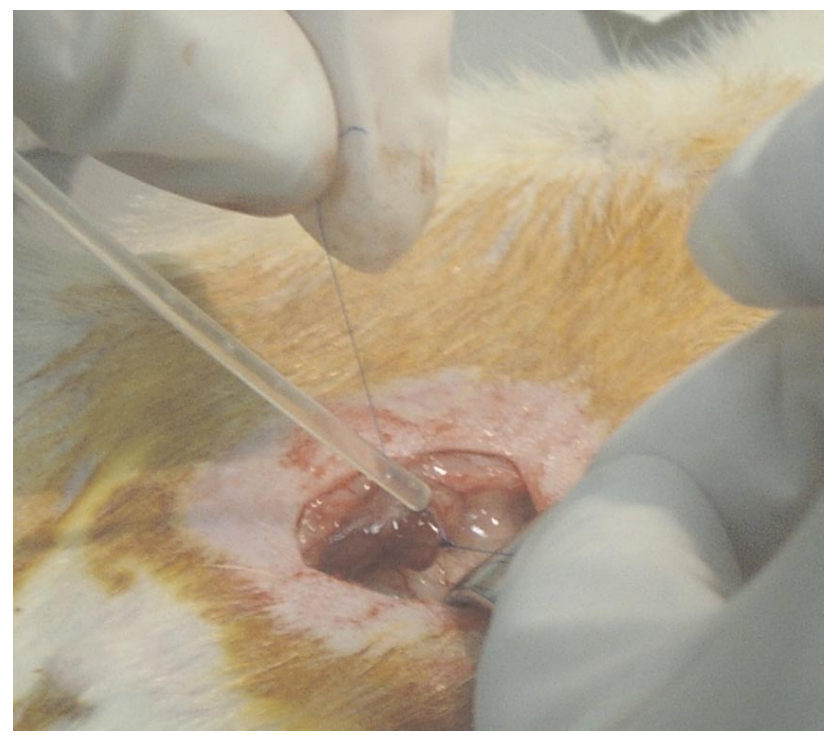

Figura 1 - Aplicação do adesivo cirúrgico BioGlue $®$.

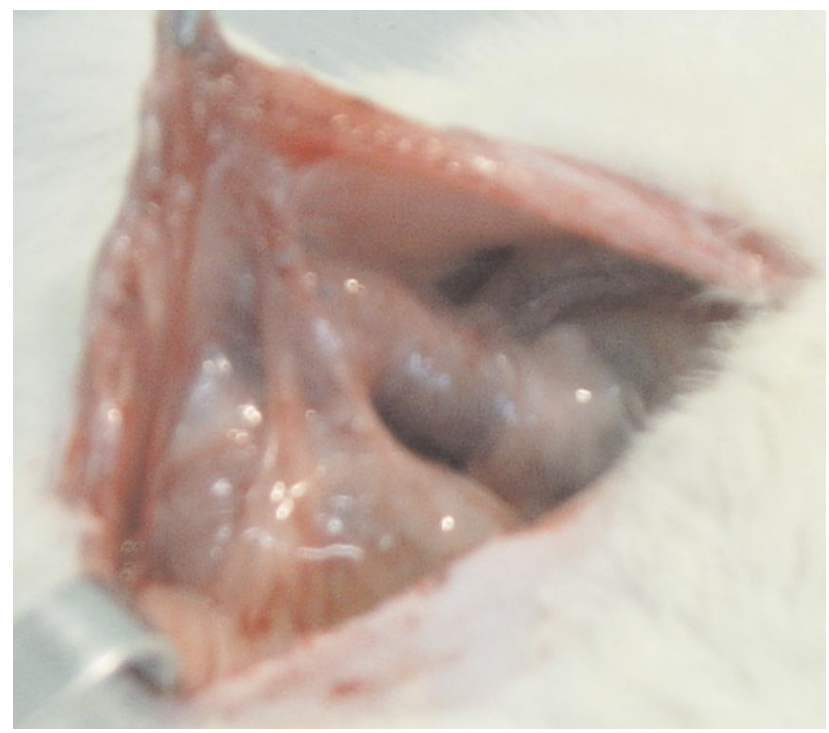

Figura 2 - Avaliação das aderências. se a pressão correspondente como a pressão de ruptura anastomótica (figura 3).

\section{Avaliação Histológica}

Os sítios das anastomoses foram ressecados e colocados em formalina tamponada a $10 \%$, submetidos à rotina histológica e emblocados em parafina. Os cortes histológicos foram realizados através do micrótomo horizontal Yamato Koki ${ }^{\circledR}$ (Japão), em cortes de $4 \mu \mathrm{m}$ de espessura sendo corados pela hematoxilina-eosina $(\mathrm{HE})^{23}$. As lâminas, assim confeccionadas, foram examinadas em microscópio óptico, por dois patologistas, desconhecedores dos grupos.

Foram avaliadas de maneira semiquantitativa, a intensidade da resposta inflamatória, a necrose tecidual e a deposição de colágeno intersticial; utilizou-se a seguinte escala para graduação das alterações: + - leve; ++ - moderada; +++ - intensa. Determinou-se também a reação granulomatosa, a neovascularização e o tipo de infiltrado celular inflamatório.

\section{Análise Estatística}

Os dados de mortalidade foram analisados através do Teste de Quiquadrado com correção de Yates por meio de tabelas de contingência $2 \times 2$, utilizando-se o programa de análise estatística Epi-Info versão 3.3.2 para Windows (Epi-Info, CDC, Atlanta, U.S.A). Considerou-se um erro alfa de $0,05(P \leq 0,05)$ para rejeição da hipótese nula.

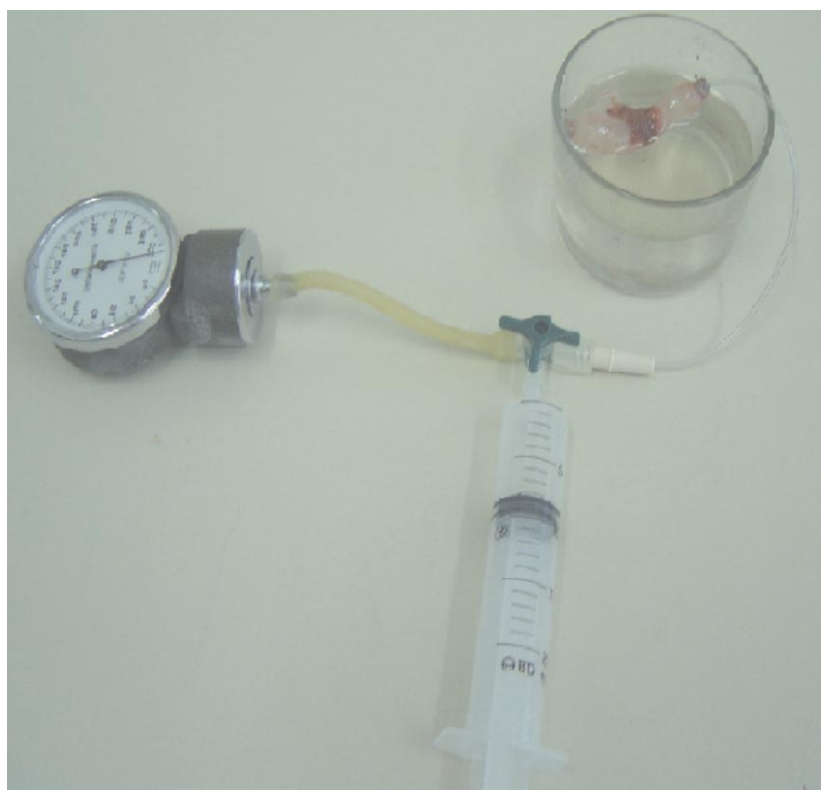

Figura 3 - Avaliação da pressão de ruptura. 


\section{RESULTADOS}

$\mathrm{Na}$ análise da mortalidade, apenas um animal do grupo $1(7 \%)$ faleceu antes do $10^{\circ}$ dia de pós-operatório e, na necropsia foi observado obstrução intestinal com grande distensão de alças. A mortalidade no grupo 2, por outro lado, foi de 10 animais $(67 \%)$ e, nos exames post-mortem realizados, foram evidenciados distensão de alças intestinais, vazamento anastomótico e, em algumas situações, franca peritonite fecal por deiscência quase que total da anastomose. A análise estatística da mortalidade entre os dois grupos, evidenciou uma diferença bastante significativa com $P=0,002$.

Dos 15 animais do grupo 2, somente 3 (20\%) sobreviveram até o $10^{\circ}$ dia de pós-operatório; 2 animais foram sacrificados no $4^{\circ}$ dia pós-cirurgia, apresentando-se bastante debilitados, com adinamia, queda dos pêlos e parada na eliminação de fezes. Nestes animais, evidenciaram-se à cirurgia, sinais de obstrução intestinal e deiscência anastomótica com peritonite localizada. Os outros 10 animais deste grupo morreram entre o $2^{\circ}$ e o $7^{\circ}$ dia de pós-operatório, todos sem apresentar evacuações.

A média da pressão de ruptura no grupo 1 foi de $163 \mathrm{mmHg}$ (para os 14 animais estudados), enquanto que no grupo 2, foi de $203 \mathrm{mmHg}$ (para os 3 ratos avaliados). O segmento que apresentou ruptura após insuflação de ar foi o proximal em relação à anastomose em 11 animais do grupo 1 (79\%), enquanto que em 3 (21\%), foi demonstrado vazamento no lado distal. Em 2 animais do grupo $2(66 \%)$, observou-se vazamento de ar na região da sutura anastomótica e, em um outro (33\%), constatou-se esse mesmo vazamento no segmento proximal.

As tabelas 1 e 2 apresentam os resultados da avaliação clínica e da pressão de ruptura nos dois grupos de animais.

Observamos nos animais em que se utilizou a cola de albumina-glutaraldeido (grupo 2), uma reação inflamatória do tipo agudo com células polimorfonucleares e neutrófilos com necrose coagulativa acentuada dos tecidos adjacentes à mesma (figura 4). Essa necrose era tanto mais intensa quanto mais próxima do local em que se aplicou a cola. No grupo 1, também evidenciamos infiltrados inflamatórios agudos, porém numa intensidade menor que no grupo 2 e mínima necrose tecidual. Aneovascularização esteve igualmente presente nos dois grupos de animais, enquanto que a reação granulomatosa só pôde ser vista no grupo controle (figura 5). A deposição de fibras colágenas intersticiais por outro lado, foi mais acentuada no grupo 1 .

Tabela 1 - Resultados da avaliação clínica e pressão de ruptura no grupo controle.

\begin{tabular}{cccccccccc}
\hline Rato $\left(\boldsymbol{n}^{\circ}\right)$ & $\begin{array}{c}\text { Peso } \\
\text { Pré-op(g) }\end{array}$ & $\begin{array}{c}\text { Peso } \\
\text { pós-op(g) }\end{array}$ & $\begin{array}{c}\text { Deiscência } \\
\text { anastomótica }\end{array}$ & $\begin{array}{c}\text { Graude } \\
\text { estenose }\end{array}$ & Peritonite & $\begin{array}{c}\text { Infecção } \\
\text { deF.O. }\end{array}$ & $\begin{array}{c}\text { Grau de } \\
\text { aderências }\end{array}$ & $\begin{array}{c}\text { Pressão de } \\
\text { ruptura(mmHg) }\end{array}$ & $\begin{array}{c}\text { Local de } \\
\text { ruptura*** }\end{array}$ \\
\hline 1 & 310 & 320 & Não & Parcial & não & não & III & 120 & Proximal \\
2 & 360 & 380 & Não & parcial & não & não & III & 180 & proximal \\
3 & 335 & 345 & não & parcial & não & não & III & 140 & proximal \\
4 & 280 & 315 & não & parcial & não & não & III & 190 & proximal \\
5 & 310 & 330 & não & parcial & não & não & III & 190 & proximal \\
6 & 400 & 385 & não & parcial & não & não & III & 160 & distal \\
7 & 410 & 405 & não & parcial & não & não & III & 170 & proximal \\
8 & 440 & 420 & não & parcial & não & não & IV & 170 & proximal \\
9 & 350 & - & não & parcial & não & não & III & 180 & distal \\
10 & 370 & 365 & não & parcial & não & não & III & 170 & distal \\
$11 *$ & 355 & - & não & total & não & não & - & & - \\
12 & 355 & 360 & não & parcial & não & não & III & 200 & proximal \\
13 & 405 & 415 & não & parcial & não & não & III & 110 & proximal \\
14 & 435 & 445 & não & parcial & não & não & III & 130 & proximal \\
15 & 395 & 395 & não & parcial & não & não & III & 180 & proximal \\
\hline
\end{tabular}

- dados não coletados; * óbito antes do $10^{\circ}$ P.O.; ** em relação à anastomose; F.O. = ferida operatória. 
Maurilio Toscano de Lucena e Cols.

Tabela 2 - Resultados da avaliação clínica e pressão de ruptura no grupo de estudo.

\begin{tabular}{cccccccccc}
\hline Rato $\left(n^{\circ}\right)$ & $\begin{array}{c}\text { Peso } \\
\text { Pré-op(g) }\end{array}$ & $\begin{array}{c}\text { Peso } \\
\text { pós-op(g) }\end{array}$ & $\begin{array}{c}\text { Deiscência } \\
\text { anastomótica }\end{array}$ & $\begin{array}{c}\text { Graude } \\
\text { estenose }\end{array}$ & Peritonite & $\begin{array}{c}\text { Infecção } \\
\text { deF.O. }\end{array}$ & $\begin{array}{c}\text { Grau de } \\
\text { aderências ruptura(mmHg) }\end{array}$ & $\begin{array}{c}\text { Pressão de } \\
\text { ruptura**al de }\end{array}$ \\
\hline $1^{*}$ & 375 & - & - & - & - & - & - & - & - \\
$2^{*}$ & 480 & - & - & - & - & - & - & - & - \\
$3^{*}$ & 330 & - & - & - & - & - & - & - & - \\
$4^{* *}$ & 460 & - & Sim & total & - & - & - & - & - \\
$5^{*}$ & 425 & - & - & - & - & - & - & - & - \\
$6^{*}$ & 370 & - & - & - & - & - & - & - & - \\
$7^{*}$ & 395 & - & - & - & - & - & - & - & - \\
8 & 395 & 345 & Não & parcial & não & não & III & 180 & linha de sutura \\
$9^{*}$ & 452 & - & - & - & - & - & - & - & - \\
$10^{*}$ & 445 & - & - & - & - & - & - & - & - \\
$11^{*}$ & 405 & - & - & - & - & - & - & - & - \\
$12^{* *}$ & 405 & - & Sim & total & sim & não & III & - & - \\
$13^{*}$ & 440 & - & Sim & - & sim & não & - & - & - \\
14 & 410 & 385 & Não & parcial & não & não & III & 200 & linha de sutura \\
15 & 410 & 385 & Não & parcial & não & não & III & 230 & proximal \\
\hline
\end{tabular}

- dados não coletados; * óbito antes do $10^{\circ}$ P.O.; **sacrificado antes do $10^{\circ}$ P.O.; *** em relação à anastomose; F.O. = ferida operatória.

Na tabela 3, são descritos os achados à microscopia óptica nos dois grupos de animais.

\section{DISCUSSÃO}

A deiscência anastomótica, após cirurgias colorretais, se constitui num evento extremamente de-

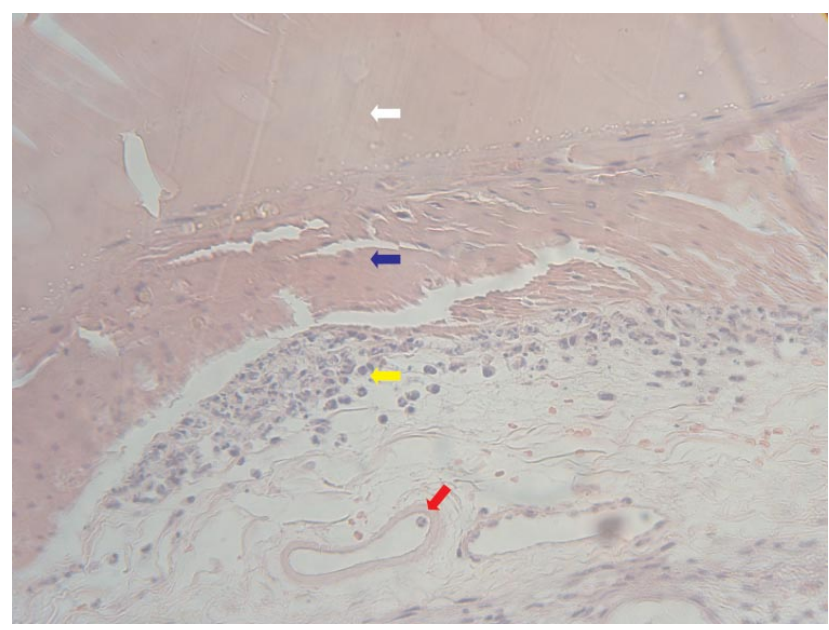

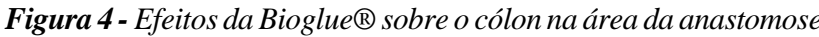
à microscopia óptica. Seta branca - cola; seta azul - necrose coagulativa; seta amarela-infiltrado neutrofilico polimorfonuclear; seta vermelha - neovascularização (coloração pela HE, 400x).

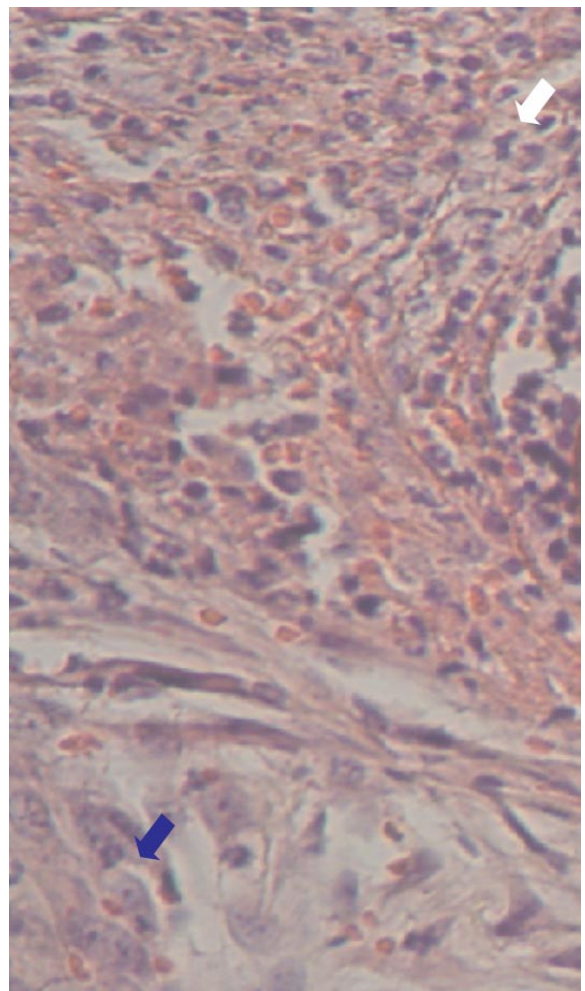

Figura 5 - Microscopia óptica do cólon na área da anastomose. Seta branca - infiltrado neutrofílico polimorfonuclear; seta azulcélula gigante tipo corpo estranho (coloração pela HE, 400x). 
Tabela 3 - Análise Histopatológica.

\begin{tabular}{|c|c|c|}
\hline Parâmetros & Grupo 1 & Grupo 2 \\
\hline Infiltrado inflamatório & Tipo agudo (PMN + neutrófilos) & Tipo agudo (PMN + neutrófilos) \\
\hline Intensidade da resposta inflamatória & ++ & +++ \\
\hline Reação granulomatosa(céls gigantes) & Presente & Ausente \\
\hline Necrose coagulativa & + & +++ \\
\hline Neovascularização & Presente & Presente \\
\hline Depósito de colágeno intersticial & +++ & ++ \\
\hline
\end{tabular}

+ - leve; ++ - moderada; +++ - intensa

$P M N=$ polimorfonuclear

vastador, não só pelo seu profundo impacto negativo sobre os resultados clínicos demonstrados pelo aumento na morbidade e nas taxas de mortalidade em até $7 x^{6,13,24,25}$, como também pelo pior prognóstico após cirurgias para câncer, com aumento nas taxas de recorrência local ${ }^{26}$, diminuição nas sobrevidas global de 5 anos e câncer específica ${ }^{27}$. Além destes fatores anteriormente considerados, o vazamento de uma anastomose intestinal, requer, na maioria das vezes, uma reintervenção cirúrgica com ressecção do local da anastomose e confecção de estomias, que, quando realizadas sobre o cólon, implica na manutenção permanente da mesma em até $60 \%$ dos $\operatorname{casos}^{5,28,29}$.

As causas atribuídas à deiscência de uma anastomose colorretal são, na sua maioria, multifatoriais, como: fatores locais (fornecimento inadequado de oxigênio, tensão mecânica elevada, grande contaminação bacteriana), fatores sistêmicos (choque, coagulopatias, malignidades, obesidade, radioterapia, imunossupressão, senilidade) e fatores de ordem técnica (tipos de fios de sutura, técnicas de sutura, duração da cirurgia) ${ }^{1-30,31}$. A despeito de todos estes conhecidos fatores de risco, os exatos mecanismos subjacentes ao déficit na cicatrização anastomótica permanecem desconhecidos ${ }^{32}$.

Os cirurgiões estão constantemente em busca de melhorias das técnicas de confecções das anastomoses, utilizando materiais de sutura que provocam menos reações inflamatórias, dispositivos mecânicos (grampeadores), anéis biofragmentáveis e colas adesivas $^{9-12}$.

Um dos recursos mais estudados ultimamente na prevenção do vazamento anastomótico, são os adesivos tissulares, que pode ser definido como uma substância capaz de manter os tecidos unidos, através da polimerização e, ao mesmo tempo, fornecer uma barreira mecânica ao vazamento do conteúdo intraluminal ${ }^{33}$. O adesivo ideal é aquele que mantém os tecidos aproximados por tempo suficiente até a cicatrização das feridas ocorrerem, sendo dissolvido ou reabsorvido em seguida, sem impedir o processo de cicatrização. Podem ser classificados como: adesivos de fibrina, compostos à base de albumina (colas de glutaraldeído), cianoacrilatos (super colas), hidrogéis (polímeros de polietilenoglicóis) e adesivos à base de colágeno (colágeno combinado com fibrina) ${ }^{34}$.

Apesar desses estudos, o verdadeiro valor da utilização de adesivos tissulares nas anastomoses colônicas, permanece um assunto controverso, com estudos clínicos prospectivos randomizados ausentes $^{12,15-20}$.

A cola a base de albumina-glutaraldeído foi recentemente aprovada para uso em humanos nos EUA como adjuvante em suturas e grampos no reparo de dissecção aórtica aguda. É formada por dois componentes: albumina sérica bovina purificada e glutaraldeído. As moléculas de glutaraldeído promovem uma ligação co-valente entre as moléculas de albumina sérica bovina e as moléculas de albumina da superfície celular e da matrix extracelular. Desta forma, cria-se um selante mecânico flexível que independe dos mecanismos de coagulação do organismo. Em vários trabalhos, tem-se avaliado o seu emprego em diversos órgãos e tecidos (pulmões, fígado, traquéia, brônquios, coronárias, vasos periféricos, reto/canal anal [fístula] e dura mater).

O presente estudo é o único na literatura consultada, que analisou os efeitos da BioGlue ${ }^{\circledR}$ no tecido intestinal e sua aplicabilidade nas anastomoses colônicas.

Utilizamos como modelo animal, ratos da raça Wistar albino, adultos, com idade variando de 90 a 150 dias, do gênero masculino e com média de peso e 
desvio padrão de $390 \pm 48 \mathrm{~g}$. Tentamos desta forma, empregar uma amostra homogênea no sentido de reduzir as variações que porventura possam existir com o uso da cola de albumina-glutaraldeído que, como já foi referido previamente, a reação da mesma com os tecidos, varia em função da localização anatômica, da espécie e da idade ${ }^{35}$. Todos os animais foram provenientes do biotério do Departamento de Nutrição do CCSUFPE e transportados para o biotério do LIKA-UFPE, onde ficaram em observação por um período mínimo de uma semana e foram submetidos a exames parasitológicos das fezes antes dos experimentos. Receberam dieta comercial Labina ${ }^{\circledR}$ contendo $23 \%$ de proteínas e água "ad libitum". Os procedimentos cirúrgicos foram realizados pelo mesmo pesquisador e no mesmo ambiente cirúrgico, num período de quatro meses, utilizando equipamentos padronizados e adaptados para o tamanho dos animais.

A metodologia utilizada foi fundamentada em relatos na literatura que, de acordo com Hillan et $a^{36}$, o melhor critério para avaliar a cicatrização colônica é através dos achados macroscópicos postmortem. Avaliamos a integridade da anastomose pela presença de sinais de vazamento contido ou difuso, além da formação de aderências. Realizamos também o estudo biomecânico da anastomose através da medição da pressão de ruptura. Procedemos à medição da pressão de ruptura por ser mais fisiológica, segundo alguns autores, que a medição da resistência de ruptura ${ }^{37}$.

Decidimos praticar a eutanásia nos animais no $10^{\circ}$ dia de pós-operatório para estudar a cicatrização da anastomose porque, sendo este um momento em que termina a fase de maior risco de deiscência das anastomoses colônicas, $5^{\circ}$ ao $7^{\circ}$ dia, poderíamos avaliar melhor a existência ou não de vazamentos.

Clinicamente foi constatado através do presente estudo, que houve uma mortalidade estatisticamente significante no grupo de animais em que se utilizou a cola de albumina-glutaraldeído $(67 \% \times 7 \%$, com $P<0,05)$ decorrente da peritonite causada pela deiscência anastomótica. Poderíamos justificar estes achados pela grande toxicidade causada pelo produto sobre o tecido colônico, levando à necrose da parede com vazamento do conteúdo fecal. Este fato foi corroborado pelas análises histológicas, onde, a necrose do tipo coagulativa foi mais intensa no grupo da cola e, em algumas amostras, se estendia até o epitélio, como pudemos detectar pela necrose de glândulas, denotando uma toxicidade transmural, envolvendo todas as camadas da parede intestinal.
Em concordância com os nossos achados, Fürst e Banerjee ${ }^{38}$, demonstraram em coelhos submetidos à ressecção pulmonar e abrasão hepática, que a aplicação da BioGlue ${ }^{\circledR}$ nesses tecidos, desencadeou uma reação inflamatória exacerbada com formação de edema e necrose local. Os autores atribuíram esses efeitos ao glutaraldeido, como puderam comprovar que, mesmo após a sua polimerização, a BioGlue $®$ libera consideráveis quantidades de glutaraldeido no líquido sobrenadante, e, a adição desse líquido a diferentes culturas de células, apresentava efeitos deletérios à viabilidade das mesmas. Da mesma maneira, Herget et $a l^{39}$, utilizando a BioGlue ${ }^{\circledR}$ em anastomoses sobre os brônquios de ovelhas, detectaram uma resposta inflamatória consistindo de neutrófilos polimorfonucleares e macrófagos infiltrando o parênquima pulmonar e a área da anastomose em que a cola foi utilizada, além de necrose tecidual localizada. LeMaire et $a l^{40,41}$, demonstraram lesão do nervo frênico quando em contato com a cola, levando a paralisia do diafragma, assim como toxicidade sobre o tecido de condução cardíaca. Os mesmos pesquisadores testaram os efeitos da BioGlue ${ }^{\circledR}$ sobre anastomoses aorto-aórticas em leitões, e observaram extensa fibrose além de estenose anastomótica 7 semanas após aplicação da cola.

A utilização da cola em cirurgias de dissecção da aorta, sua principal indicação, também tem ocasionado alguns efeitos adversos, como a maior taxa de formação de pseudoaneurismas; o que tem sido atribuído a uma lesão tecidual local provocada pela toxicidade do produto ${ }^{42,44}$. Têm-se observado em espécimes cirúrgicos, mesmo após um período de três meses da utilização da BioGlue ${ }^{\circledR}$, um processo inflamatório ativo e severo circundando a cola remanescente com vários granulócitos e histiócitos e uma acentuada reação tipo corpo estranho com numerosas células gigantes multinucleadas, o que não foi observado no nosso trabalho, provavelmente pelo curto período de análise das amostras (10 dias após aplicação da cola).

Além da ação tóxica do glutaraldeido sobre os tecidos, acredita-se também, que a polimerização do composto, possa levar a uma espécie de anel rígido, provocando fibrose e estenose, quando aplicado de maneira circular ${ }^{38}$, como foi realizado em nosso estudo, embora tal fato não tenha substrato histopatológico já que o depósito de colágeno intersticial foi até mais intenso quando se utilizou apenas o fio de sutura. Mais uma vez, acreditamos que o período de tempo foi insu- 
ficiente para observarmos a formação do colágeno maduro e conseqüente fibrose.

Pesquisadores têm sugerido um risco potencial durante a aplicação da cola, de se introduzir na corrente sangüínea, quantidades de glutaraldeído livre, nas cirurgias com circulação extracorpórea e sistemas de reaproveitamento do sangue ${ }^{38}$. Este é um risco que deve ser levado em consideração nas cirurgias cardíacas, mas não nos procedimentos que envolvam anastomoses intestinais, pois, acreditamos, que o composto não tenha acesso à circulação sangüínea; reforçando esta hipótese, nas amostras analisadas, não detectamos resíduos da cola no interior de vasos.

\section{CONCLUSÃO}

O presente trabalho nos permite concluir que, o uso da Bioglue ${ }^{\circledR}$ nas anastomoses colônicas realizadas em ratos, promoveu um aumento na morbimortalidade que foi estatisticamente significante comparado ao grupo em que se realizou apenas anastomoses com fios de sutura.

\begin{abstract}
The great part of the morbimortality associated with the colorretal surgery, is related with the anastomotic dehiscence. Experimental trials on the utility of tissue adhesives in the colonic anastomosis are controversial, as well as prospective randomized clinical studies are absent. BioGlue ${ }^{\circledR}$ Surgical Adhesive(BSA) is a two-component surgical adhesive composed of purified bovine serum albumin and glutaraldehyde. The glutaraldehyde molecules covalently bond (cross-link) the BSA molecules to each other and, upon application, to the tissue proteins at the repair site. The aim of this study is to evaluate the effectiveness of the BioGlue $₫$ in the prevention of the anastomotic colonic dehiscence in rats. Thirty male Wistar rats had been used. The colocolonic anastomosis was confectioned with separate stitches with polypropylene 5-0 (group 1) and the application of the BioGlue $\AA$ Surgical Adhesive (group 2). The formation and extension of the adhesions, the histological alterations and the rupture pressure had been evaluated. In the group 1, we have only $7 \%$ of mortality (01 animal), being evidenced in the autopsy, intestinal obstruction with major bowel distension. The mortality in group 2, on the other hand, was 67\% (10 animals), being observed: bowel distension, anastomotic dehiscence and, in some situations, fecal peritonitis because of anastomotic total dehiscence. We concluded in the present study that, the use of BioGlue ${ }^{\circ}$ Surgical Adhesive in colonic anastomosis in rats, is associated with an increase of the morbimortality in comparison with conventional suture which was statistically significant.
\end{abstract}

Key words: Bioglue $®$, colonic anastomosis, dehiscence.

\section{REFERÊNCIAS}

1. Cronin K, Jackson DS, Dunphy JE. Changing bursting strength and collagen content of the healing colon. Surg Gynecol Obstet 1968; 126: 747-53.

2. Docherty JG, McGregor JR, Akyol AM, Murray GD, Galloway DJ. Comparison of manually constructed and stapled anastomoses in colorectal surgery. West Scotland Highland Anastomosis Study Group. Ann Surg 1995; 221: 176-84.

3. Fingerhut A, Elhadad A, Hay JM, Lacaine F, Flamant Y. Infraperitoneal colorectal anastomosis: hand-sewn versus circular staples. A controlled clinical trial. French Associations for Surgical Research. Surgery 1994; 116: 484-90.

4. Fingerhut A, Hay JM, Elhadad A, Lacaine F, Flamant Y. Supraperitoneal colorectal anastomosis: hand-sewn versus circular staples. A controlled clinical trial. French Associations for Surgical Research. Surgery 1995; 118: 479-85.

5. Karanjia ND, Corder AP, Bearn P, Heald RJ. Leakage from stapled low anastomosis after total mesorectal excision for carcinoma of the rectum. Br J Surg 1994; 81: 1224-6.
6. Fielding LP, Steward-Brown S, Blesovsky L, Kearny G. Anastomotic integrity after operations for large-bowel cancer: a multicentre study. BMJ 1980; 281: 411-4.

7. Hunt TK, Hawley PR, Hale J, Goodson W, Thakral KK. Colon repair: the collagenous equilibrium. In: Hunt TK (ed.) Wound Healing and Wound Infection: Theory and Surgical Practice. New York: Appleton-Century-Crofts, 1980; 153-9.

8. Shandall A, Lowndes R, Young HL. Colonic anastomotic healing and oxygen tension. Br J Surg 1985; 72: 606-9.

9. Ballantyne GH, Burke JB, Rogers G, Lambert EG, Boccia J. Accelerated wound healing with stapled enteric suture lines. An experimental study comparing traditional sewing techniques and a stapling device. Ann Surg 1985; 201: 360-4.

10. Hardy TG, Pace WG, Maney JW, Katz AR, Kaganov AL. A biofragmentable ring for sutureless bowel anastomosis. An experimental study. Dis Colon Rectum 1985; 28: 484-90.

11. Healey JE, Clark RL, Gallager HS, O'Neill P, Sheena KS. Non-suture repair of blood vessels. Am J Surg 1962; 155 : $817-26$

12. Jansson OK, Zilling TL, Walther BS. Healing of colonic anastomosis: comparative experimental study of glued, 
manually sutured and stapled anastomoses. Dis Colon Rectum 1991; 34: 557-62.

13. Golub R, Golub RW, Cantu R Jr, Stein HD. A multivariate analysis of factors contributing to leakage of intestinal anastomoses. J Am Coll Surg 1997; 184: 364-72.

14. Goligher JC, Graham NG, De Dombal FT. Anastomotic dehiscence after anterior resection of rectum and sigmoid. Br J Surg 1970; 57: 109-18.

15. Weiss M, Haj M. Gastrointestinal anastomosis with histoacryl glue in rats. J Invest Surg 2001; 14: 13-9.

16. Giray CB, Sungur A, Atasever A, Araz K. Comparison of silk and n-butyl-2-cyanoacrylate on the healinhg of skin wounds. A pilot study. Aust Dent J 1995; 40: 43-5.

17. West of Scotland and Highland Anastomosis Study Group. Suturing or stapling in gastrointestinal surgery: a prospective randomized study. Br J Surg 1991; 78: 337-41.

18. van der Ham AC, Kort WJ, Weijma IM, van der Ingh HF, Jeekel J. Effect of fibrin sealant on the healing of colonic anastomosis in the rat. Br J Surg 1991; 78: 49-53.

19. Nordkild P, Hjortrup A, Kjaergaard J. Tissue adhesives and intestinal anastomoses. Ann Chir Gynaecol 1986; 75: 205-8.

20. Houston KA, Rotstein OD. Fibrin sealant in high-risk colonic anastomoses. Arch Surg 1988; 123: 230-4.

21. Kanellos I, Mantzoros I, Demetriades H, Kalfadis S, Kelpis T, Sakkas L, Betsis D. Healing of colon anastomoses covered with fibrin glue after immediate postoperative intraperitoneal administration of 5fluorouracil. Dis Colon Rectum 2004; 47: 510-15.

22. Mazuji MK, Kalambaheti K, Pawar B. Prevention of adhesions with polyvinylpyrolidone. Arch Surg 1964; 89: 1011.

23. Culling CFA, Allison RT, Barr WT. Cellular Pathology Technique. 4 th ed. London: Butterworths; 1985.

24. Pickleman J, Watson W, Cunningham J, Fisher SG, Gamelli R. The failed gastrointestinal anastomosis: an inevitable catastrophe? J Am Coll Surg 1999; 188: 473-82.

25. Alves A, Panis Y, Trancart D, Regimbeau JM, Pocard M, Valleur P. Factors associated with clinically significant anastomotic leakage after large bowel resection: multivariate analysis of 707 patients. World J Surg 2002; 26: 499-502.

26. Branagan G, Finnis D. Prognosis after anastomotic leakage in colorectal surgery. Dis Colon Rectum 2005; 48: 1021-26.

27. Walker KG, Bell SW, Rickard MJ, Mehanna D, Dent OF, Chapuis PH, Bokey

EL. Anastomotic leakage is predictive of diminished survival after potentially curative resection for colorectal cancer. Ann Surg 2004; 240(2): 255-9.

28. Graf W, Glimelius B, Bergström R, Påhlman L. Complications after double and single stapling in rectal surgery. Eur J Surg 1991; 157: 543-57.

29. HallböökO, Sjödahl RJ.Anastomotic leakage and functional outcome after anterior resection of the rectum. Br J Surg 1996; 83: 60-2.

30. Yamakawa T, Patin CS, Sobel S, Morgenstern L. Healing of colonic anastomoses following resection for experimental 'diverticulitis'. Arch Surg 1971; 103: 17-20.
31. Vignali A, Fazio VW, Lavery IC, et al. Factors associated with the occurrence of leaks in stapled rectal anastomoses: a review of 1,014 patients. J Am Coll Surg 1997; 185:105-13.

32. Witte MB, Barbul A. Repair of full-thickness bowel injury. Crit Care Med 2003;31:S538-46.

33. Reece TB, Maxey TS, Kron IL. A prospectus on tissue adhesives. Am J Surg 2001; 182: 40S-4S.

34. Waxman BP. Adhesives and adhesions: intestinal surgery on a sticky wicket!(editorial). ANZ J Surg 2004; 74: 1037-8.

35. Le Maire, Schmittling ZC, Coselli JS, Undar A, Deady BA, Clubb FJ Jr, Fraser CD Jr. BioGlue surgical adhesive impairs aortic growth and causes anastomotic strictures. Ann Thorac Surg 2002; 73(5); discussion 1506.

36. Hillan K, Nordlinger B, Ballet F, Puts JP, Infante R. The healing of colonic anastomoses after early intraperitoneal chemotherapy. An experimental study in rats. J Surg Res 1988; 44: 166-71.

37. Saglam A, Yesilkaya A, Harmanda R, Yesilkaya Y. Effect of Ceftazidime on healing of the fascia and colonic anastomosis. Kolon ve Rektum 1991; 1: 41-4.

38. Fürst W, Banerjee A. Release of glutaraldehyde from an albumin-glutaraldehyde tissue adhesive causes significant in vitro and in vivo toxicity. Ann Thorac Surg 2005;79:1522-9.

39. Herget GW, Kassa M, Riede UN, Lu Y, Brethner L, Hasse J. Experimental use of an albumin-glutaraldehyde tissue adhesive for sealing pulmonary parenchyma and bronchial anastomoses. Eur J Cardiothorac Surg 2001;19:4-9.

40. Le Maire SA, Schmittling ZC,U“ ndar A, et al. A new surgical adhesive (BioGlue) causes acute phrenic nerve injury and diaphragmatic paralysis. J Surg Res 2000;93:354.

41. LeMaire SA, Conklin LD, Schmittling ZC, et al. Chlorohexidine gluconate gel protects the myocardium and sinoatrial node during application of BioGlue surgical adhesive. J Surg Res 2001;100:290-1.

42. Kazui T, Washiyama N, Bashar AHB, et al. Role of biologic glue repair of proximal aortic dissection in the development of early and midterm redissection of the aortic root. Ann Thorac Surg 2001;72:509-14.

43. Downing SW. What are the risks of using biologic glues? Ann Thorac Surg 2003;75:1063-4.

44. Bavaria JE, Pochettino A, Brinster DR, et al. Prospective randomized study of BioGlue tissue adhesive during repair of acute type A aortic dissection. Presented at the $81^{\text {st }}$ Annual Meeting of the American Association for Thoracic Surgery, San Diego, CA, May 7, 20.

\section{Endereço para correspondência:}

\section{MAURILIO TOSCANO DE LUCENA}

Rua Conselheiro Portela, 130B/201, Graças. Recife-PE

CEP: 52020-030

Fone: (81) 3242-9747

E-mail:mtlucena@superig.com.br 